2. Blake G], Ridker PM. Novel clinical markers of vascular wall inflammation. Circ Res 200I, 89:763-71.

3. Ridker PM, Hennekens CH, Buring JE, Rifai $\mathrm{N}$. C-reactive protein and other markers of inflammation in the prediction of cardiovascular disease in women. N Engl J Med 2000, 342:836-43.

4. Ridker PM, Rifai N, Clearfield M, Downs JR, Weis SE, Miles JS, et al. Measurement of Creactive protein for the targeting of statin therapy in the primary prevention of acute coronary events. N Engl | Med 200I, 344:1959-65.

\section{Gimecologia \\ NOVO CONSENSO PARA A SÍNDROME DOS OVÁRIOS POLICÍSTICOS}

Os critérios diagnósticos da síndrome dos ovários policísticos (SOP) foram recentemente revisados pelo The Rotterdam ESHRE/ ASRM - sponsored PCOS consensus workshop group, 2004; os postulados em 1999 requeriam dois fatores diagnósticos e os atuais requerem dois de três fatores.

\section{Comentário}

Critérios em 1999 (l e 2)

1. Anovulação crônica

2. Sinais clínicos elou bioquímicos de hiperandrogenismo, excluindo-se outras etiologias. Critérios revisados em 2004 (2 de 3)

1. Oligomenorréía elou anovulação

2. Sinais clínicos elou bioquímicos de hiperandrogenismo, excluindo outras etiologias de hiperandrogenismo como hiperplasia congênita adrenal, tumores secretores de androgênios e sindrome de Cushing

3. Ovários policísticos caracterizados pelo exame ultra-sonográfico padronizado, ou seja, presença de pelo menos um dos seguintes achados: 12 ou mais folículos medindo entre $2-9 \mathrm{~mm}$ de diâmetro ou volume ovariano aumentado $\left(>10 \mathrm{~cm}^{3}\right)$. Caso se constate a presença de um folículo dominante (> 10 $\mathrm{mm}$ ) ou de corpo lúteo, o ultra-som (US) deverá ser repetido no próximo ciclo.

Outros detalhes diagnósticos estão publicados neste consenso.
Rastreamento de desordens metabólicas

1. Nenhum teste de resistência insulinica é necessário para o diagnóstico de SOP, nem para o tratamento a ser instituído.

2. Mulheres obesas com SOP devem ser rastreadas para a sindrome metabólica, incluindo avaliação da intolerância à glicose por meio da realização do teste de tolerância oral à glicose (GTT).

3. Outros estudos são necessários em muIheres não obesas com SOP para se determinar a real utilidade destes testes; no entanto, devem ser sempre solicitados caso estejam presentes fatores de risco adicionais para resistência insulínica, como história familiar de diabetes.

Critérios para a identificação da síndrome metabólica em mulheres com SOMP:

A constatação de pelo menos três de cinco fatores de risco qualifica a presença da síndrome metabólica:

\begin{tabular}{lc}
\hline $\begin{array}{l}\text { 1. Obesidade abdominal } \\
\text { (medida da circunferência da cintura) }\end{array}$ & Valor de corte \\
2. Triglicérides & $\geq 88 \mathrm{~cm}$ \\
3.HDL-Colesterol & $<50 \mathrm{mg} / \mathrm{dl}$ \\
4.Pressão sanguínea & $\geq 130 / \geq 85 \mathrm{~mm} / \mathrm{dl}$ \\
5. Glicemia de jejum & $100-126 \mathrm{mg} / \mathrm{dl}($ jejum) \\
e duas horas após o GTT & $e / 0 u / 40-199 \mathrm{mg} / \mathrm{dl}$ \\
& $(2 \mathrm{~h}$ após GTT) \\
\hline
\end{tabular}

A identificação da resistência insulínica (RI) não é necessária para firmar o diagnóstico de SOP; entretanto, ainda há controvérsias sobre necessidade de se pesquisar rotineiramente $R /$ em todas as portadoras da sindrome (obesas e não obesas). Devido a essas controvérsias (principalmente a de se identificar a resistência insulínica nas pacientes não obesas com SOP), indicamos em nosso serviço a avaliação rotineira da glicemia e da insulina de jejum em todas as portadoras com SOP, bem como preconizamos o cálculo do Quicki (Quantitative insulin-sensitivity check index).

O clínico deve estar atento para esta complexa síndrome, que desde sua descrição inicial em 1935 tem sido alvo de diversos consensos; neste último ressurgiu a valorização dos aspectos morfológicos dos ovários e manteve-se a importância dos aspectos metabólicos. A relação $L H / F S H>2$, considerada por muitos como patognomônica deste tipo de anovulação, não foi incluída neste consenso pois não está presente em todos os casos.

Rui Alberto ferriani

Referências

I. Balen AH, Laven JSE, Dewailly D. Ultrasound assessment of the polycystic ovary: international consensus definition. Hum Reprod 2003; 9(6):505-14.

2. The Rotterdam ESHRE/ASRM-sponsored PCOS consensus workshop group. Revised 2003 consensus on diagnostic criteria and long-term health risks to polycystic ovary syndrome (PCOS). Hum Reprod 2004; 19(I):4|-7.

\section{Obsecticia \\ DIRETRIZES PARA 0 CÂNCER DE MAMA GESTACIONAL}

A tendência atual em se retardar a gravidez para a terceira ou quarta décadas de vida, associada a maior risco de câncer de mama em pacientes jovens e maior sobrevida dessas pacientes, contribuem para maior incidência de câncer de mama gestacional (CMG). Considerando seu diagnóstico durante gravidez e até 12 meses após o parto, a incidência varia entre $0,7 \%$ e 3,9\%, estabelecendo freqüência de um caso para 3.000 ou 10.000 partos.

Diante das alterações fisiológicas gestacionais, a vascularização aumentada, a hipercelularidade, o edema, a secreção láctea, intensificam a densidade do parênquima, diffcultam o exame físico, reduzem o contraste do tecido adiposo e prejudicam a interpretação da mamografia e ultra-sonografia.

A tolerância imunológica gestacional, constatada pela ausência de antígenos específicos (MHC-I), presença de moléculas HLA e redução dos anticorpos bloqueadores, restringe a imuno-reatividade.

O maior percentual de casos com linfonodos positivos, os receptores de estrogênio (ER) ou progesterona (PR) negativos, C-erbB2 e p53 mais elevados e os índices elevados de mutação $B R C A$, comparando-se com o câncer de mama esporádico, depreendem agressividade tumoral. 